ISSUES AND INNOVATIONS IN NURSING EDUCATION

\title{
Measuring the socialization of graduate and diplomate nurses using the Corwin Role Orientation Scale
}

\author{
Heidi R. Taylor BA MA \\ Research Associate, School of Health Policy and Practice, University of East Anglia, Norwich, UK \\ Elizabeth Westcott MSc Dip Man RNT Cert Ed RGN \\ Principal Lecturer, School of Health Care, Oxford Brookes University, Oxford, UK \\ and Helen P. Bartlett BA MSc PhD RGN RHV \\ Deputy Head (Research), School of Health Care \\ Director, Oxford Centre for Health Care Research \& Development, Oxford Brookes University, Oxford, UK
}

Submitted for publication 12 May 1999

Accepted for publication 8 August 2000

Correspondence:

Helen Bartlett,

Oxford Centre for Health Care Research

and Development,

Oxford Brookes University,

44 London Road,

Headington,

Oxford OX3 7PD,

UK

E-mail: hbartlett@brookes.ac.uk
TAYLOR H.R., WESTCOTT E. \& BARTLETT H.P. (2001) Journal of Advanced Nursing 33(1), 20-28

Measuring the socialization of graduate and diplomate nurses using the Corwin Role Orientation Scale

The nature of United Kingdom (UK) nursing education has changed significantly as the responsibility has been transferred from hospitals to the University sector. More information is needed on the outcome of the Project 2000 diploma and degree courses given the rapidly changing health care context. This paper focuses on the role socialization of graduate and diploma nurses. As part of a larger study, this research investigated the role orientations of 52 nursing graduates and 28 diplomates from two different universities at three time points; on graduation and at 6 and 12 months postgraduation. The Corwin Role Orientation Scale was selected and modified for the study. It comprised of three separate scales measuring professional, bureaucratic and service orientation. The data from the two groups of nurses were examined to identify nurses' ideal role orientations and role discrepancies over the transitionary period from graduate to qualified nurse. Although the results showed observed differences between the groups over time, none of these differences were statistically significant. The findings raise a number of questions about the value of the instrument as a measure in the contemporary nursing context. Furthermore, each of the Corwin subscales had a low internal reliability. A possible explanation may be that the instrument, which was developed in the United States of America (USA) in the 1960s, and modified, for this study, has little relevance for contemporary UK nursing. The study findings are also limited by the small size of the sample. In spite of these limitations, the study suggests there are few differences between the role orientations and socialization experiences of UK nursing graduates and diplomates. Indeed, both programmes commonly take place in university settings and students receive the same amount of clinical experience. Further instrument development and exploratory research is recommended to identify the role socialization and orientations of UK nurses through larger national studies.

Keywords: role socialization, role orientation, degree programmes, diploma programmes, Project 2000. 


\section{Introduction}

The nature of United Kingdom (UK) nursing education has changed significantly with the increasing availability of nursing degree courses and the introduction of the Project 2000 nursing diploma (UKCC 1999). Given the changes that have occurred with the transfer of nursing education from hospitals to the university sector, there is an increasing need to investigate the outcomes of current nurse education programmes, such as role orientation and socialization. The concept of socialization in professional groups has been studied for many years and has been described by Merton et al. (1957) as 'the process by which people selectively acquire the values and attitudes, the interests, skills and knowledge - in short the culture - current in the group of which they are, or seek to become a member' (cited in Melia 1984, p. 139). A key dimension of this process is the interaction with people who are significant to the individual.

Changes in educational socialization can create role conflict for nurses caused by role discrepancies between the nurse's ideal conception of nursing and their actual observed experience in the clinical setting. Persistent or severe role strain can lead to stress, apathy, frequent job changes, burnout and exit from the profession (Jamal 1984, Shead 1991). Nurses educated through degree and Project 2000 programmes may differ in their ideal conceptions of the nursing role and experience different role discrepancies when faced with the realities of the work setting.

The aim of this longitudinal study was to measure and compare the outcomes of two degree and diploma nurse education programmes in the UK. Nurse competence, role orientation and career aspirations were measured in a comparative study of two programmes (Bartlett et al. 1998). This paper focuses on the role orientation component of the study.

\section{Literature Review}

The literature review aimed to identify the key characteristics of role orientation and socialization and to identify a suitable research instrument for the study.

\section{The role orientation of nurses from different educational programmes}

Historically, the main type of nurse training in the UK was the registered general nurse (RGN) course, which was usually provided by a school of nursing attached to a large hospital. Nursing degree programmes developed from the late 1950s onwards in the UK, but these were few in number. In the 1980s, the Project 2000 diploma course was gradually introduced and UK diploma and degree programmes are now university-based. This move offers student nurses the benefits of complete student status, more resources, exposure to a variety of academic staff, the opportunity to develop critical thinking and to participate in a more questioning environment (Dunn 1991, Fitzpatrick et al. 1993, Winson 1993). However, concerns voiced by clinical staff and educators over university-based nurse education programmes highlight the reduced amount of time spent gaining clinical experience in the ward, experiencing specialized skills and critical incidents, and the consequent lack of opportunity to put theory into practice (Shead 1991, Wilson \& Startup 1991, Gerrish 1992, Robinson 1992, Prowse 1996). Research into whether this has an impact on role socialization of nurses is therefore very important.

Research into the role orientation of nurses educated on different educational programmes has been confined mainly to the United States of America (USA) and was most widely undertaken prior to 1990 at a time when changes were occurring in nurse education (Corwin 1961a, 1961b, Corwin \& Taves 1962, Davis \& Oleson 1964, Kramer 1970, Murray \& Morris 1982, Ahmadi et al. 1987, Itano et al. 1987, Green 1988, Marshall 1988). There have been no published quantitative longitudinal studies of the role orientations of diploma and degree nurses in the UK. However, there has been one recent, qualitative, comparative research study on the differences between traditional RGN diploma and degree education for UK nurses (Fitzpatrick et al. 1996). The other relevant UK research is also mainly qualitative and explores the meaning of nurse experience and not the measurement of educational outcomes (Kelly 1991, 1996, Wilson \& Startup 1991).

Due consideration needs to be given to differences in terminology if a comparison is to be made between UK and USA research. Diploma students in the USA tend to have a hospital-based education (at least historically) whereas baccalaureate degrees (BSN) and associate degrees are more college/university based. Much of the past USA research literature investigating the role orientations of nurses uses Corwin's (1961a, 1961b) Nursing Role Orientation Scale which measures the ideal role conception and actual observed role conception of the nurse in the bureaucratic, professional and service domains of their roles.

Studies which have measured nurses' role orientations during their early period as qualified nurses using Corwin (1961a, 1961b) have shown an increased bureaucratic orientation, especially in degree nurses. Whereas diploma nurses tend to maintain their current and usually high bureaucratic orientation (Corwin 1961a, 1961b, Corwin \& 
Taves 1962, Kramer 1970, Green 1988). These degree students have a higher discrepancy between their ideal and actual role conception and are attempting to balance their high professional values with the bureaucratic requirements of the clinical work setting. Over a longer period of time, they tend to maintain their high professional orientation although it may have been compromised in order to fit in with the actual bureaucratic requirements of the clinical setting. When they have been qualified for a considerable period, degree nurses feel they are more able to begin to act upon their professional values and as autonomous agents of change within the bureaucratic system (Corwin \& Taves 1962, Kramer 1968, Ahmadi et al. 1987, Kelly 1996).

\section{Changes in the educational socialization of nurses}

Because the structure of UK nursing education has changed, there is greater diversity of educational levels for entry into the nursing profession. The US research literature on this subject published in the 1960s and 1970s has compared the socialization of nurses on different educational programmes, i.e. diploma, associate degree and degree (Corwin 1961a, 1961b, Corwin \& Taves 1962, Kramer 1968, 1970, Bullough \& Sparks 1975, Hover 1975). These studies are mainly quantitative in design and have produced some notable results. Bullough and Sparks (1975) found that most students just wanted to help people and therefore chose to do nursing, thinking less about the philosophical position of a particular institution. Hover (1975) examined the goals and attitudes of students and whether these altered depending on the type of the educational background experienced. In a study of 103 degree and diploma educated nurse graduates, it was found that the degree graduates were less restricted in their preferences for patients and were more satisfied with their education. However, as the diploma students undertook further education towards degree level, their opinions were more in line with those of the degree graduates.

A qualitative longitudinal approach to the study of nurses' educational socialization has been used in some research (Simpson 1967, Olesen \& Whittaker 1968, Simpson 1979). Melia (1987) undertook a qualitative study of 40 nurses' experience of their educational socialization in the RGN programme. While the education of nurses has changed significantly since Melia's study and socialization and role orientation of nurses may now differ, the results are still relevant to examine. The study highlighted the differences between the classroom setting and clinical practice areas and the effect of this continued segmentation on students' socialization. Students learnt to fit in, to say the right thing at the right time and to just get through a placement. While this was potentially helpful for students once they qualified in terms of their ability to adapt to circumstances, such experiences did not necessarily assist in their professional development (Melia 1987).

\section{Nursing roles}

Roles define the way individuals act by the internalization of certain values and norms and participation in social action among other role references. The acquisition of a new role initiates the individual into a particular social group. Indeed, role-taking links the individual with the group (du Toit 1995). Mead (1934) identified role-taking as a method of developing the self concept and social identity of the individual. Role-taking and the socialization process takes place essentially through the preregistration programme in both clinical and educational settings. Individuals who take on the role of nurse are not only assimilating new facts and learning new skills, they become immersed in a new culture with norm and value expectations. This simultaneously develops an identity, self worth, interaction with role models and judgements of others' reactions to the role (Narcisco Throwe \& Fought 1987).

\section{Others' role expectations of nurses from different educational programmes}

The expectations of nurses and their career advancement is not necessarily linked to educational achievement but dependent upon experience (Schank \& Stollenwerk 1988, Bircumshaw 1989a). Nevertheless, there has been an expectation that degree students should have a wider knowledge base and capabilities (Reid et al. 1987) and demonstrate autonomy, critical decision-making and reflexivity (Bircumshaw 1989a). These qualities are also expected from the Project 2000 diploma students now (Casey 1996, Jasper 1996). In the UK, however, the career structure for nurses is not linked to educational achievement and there are no distinct career pathways for nurses who have been educated through different programmes.

\section{Education and clinical settings: putting theory into practice}

Socialization into these two areas is not a homogenous process. Again, Shead (1991) identifies the ideal, the product of educational socialization and the actual, the clinical setting in which nurses must work, as the most dominant area of 
conflict for the new nurse. Ideally, nurse socialization should take place between the two areas but Melia (1984) indicates that nursing students in her UK study viewed these two areas as distinct. Incongruencies between these two settings can result in role discrepancies for the nurse being socialized and hence lead to role conflict. The more the perceived and actual role difference, the more the role conflict. Corwin and Taves (1962) found that degree educated nurses in the USA suffered the most role conflict because they possessed higher professional ideals enculturated through the educational experience which conflicted with the actuality of the bureaucratic setting. Yung (1996) noted that on the hospital-based certificate programme in Hong Kong, nurses experienced less role conflict than the degree programme nurses as they had spent more time in the hospital's bureaucratic setting and were enculturated into the actual not the ideal role.

\section{Transition from the role of student to the role of nurse}

Newly qualified nurses are in a delicate period of transition involving the consolidation of their educational socialization and the commencement of secondary socialization into their first workplace. If there are insufficient professional role models, new nurses, be they students or newly qualified, will endeavour to 'fit in' as best as they can, quite often at the risk of merely getting the job carried out rather than practising their ideal conception of nursing (Wilson \& Startup 1991, Greenwood 1993). Good educational and clinical role models can ease the student nurse's transition to the clinical setting and into the role of the qualified nurse. The UK research has shown that the capacity of role models and mentors to help student nurses is restricted by constraints of time, unit management, the increased need for cost efficiency, and high patient throughput (Greenwood 1993, Atkins \& Williams 1995, Prowse 1996). Negative reactions from clinical staff, or from experiences in the clinical setting can challenge newly qualified nurses' ideal role conceptions and lead to conflict. Further research into nurses' actual and ideal nursing role conceptions, in particular the differing conceptions of service, bureaucracy and profession is needed if the potential for role conflict is to be understood and addressed (Kelly 1991).

\section{The study}

\section{Research design}

This study was part of a larger investigation, which compared graduates and diplomates over a 12 -month period following registration. The findings on career aspirations and compet- ence have been reported elsewhere (Bartlett et al. 1999, 2000). The aims of this part of the study were threefold:

- To measure the role orientation/socialization of graduates during their first year of practice.

- To identify whether role orientation/socialization is influenced by educational background.

- To assess the appropriateness of the Corwin Nursing Role Conception Scale in measuring nurses' role socialization in the UK.

Diploma and degree nurses' role orientations were measured at three points over a 1-year period: on graduation, after 6 months and at 12 months. The ideal role orientations and role discrepancies of the two groups were compared over this period.

\section{Sample}

The sample comprised one cohort of degree graduates from the adult nursing field at Oxford Brookes University $(n=81)$ and one cohort of Project 2000 diploma graduates from another University $(n=41)$. The same questionnaire was sent to the degree and diploma graduates on completion of their courses at 6 and 12 months postgraduation. Thirty-five degree nurse graduates and 21 diploma nurse graduates responded to all the three questionnaires over the 12 months.

\section{Instrument}

Corwin's Nursing Role Conception Scales (Corwin 1961a, 1961b) were used to measure the role orientation of the sample. Corwin identified three conceptions of nursing and from these devised an instrument with three domains: bureaucratic, professional and service. Each scale has between six and seven hypothetical situations to which the respondent is asked to give two answers. First, in part 'a' of each question the respondent is asked to indicate, on a 5point Likert scale, the extent to which the situation should be ideal nursing and in part ' $\mathrm{b}$ ' to indicate the extent to which they have actually observed the situation in practice. For example,

Question 2-2: A registered nurse does not carry out what she is told to so unless she is satisfied that it is best for the welfare of the patient.

- Do you think this is what a registered nurse 'should' do?

- Do you think this is what registered nurses at your hospital actually 'do' when the occasion arises?

Responses were recorded using a 5-point Likert scale, where $1=$ strongly disagree, $2=$ disagree, $3=$ undecided, $4=$ agree and $5=$ strongly agree. Corwin (1961a, 1961b) identified the three domains of the nurses' role which are measured separately (see Table 1).

As the instrument was originally developed in the early 1960s in the USA, some modifications were necessary so it 
Table 1 Constructs used in the measurement of role orientation

\begin{tabular}{ll}
\hline Construct & Description \\
\hline Bureaucracy & $\begin{array}{c}\text { Hospital rules and regulations presented in policy } \\
\text { and standards (six items) } \\
\text { Pevelopment and maintenance of professional } \\
\text { values through professional bodies, continual } \\
\text { education and academic reading (seven items) }\end{array}$ \\
Service & $\begin{array}{c}\text { The calling to nursing; primarily concerned } \\
\text { with the patient as a person (seven items) }\end{array}$ \\
\hline
\end{tabular}

related to contemporary nursing in the UK. Changes in the wording were made for ease of comprehension and one question on spirituality of the nurse was omitted, as its relevance to contemporary nursing in the UK was questioned.

\section{Scoring of the instrument}

The sum of the Likert responses to part 'a' of each question in each scale constituted the ideal nursing role score and the sum of responses to part ' $b$ ' of each individual scale constituted the observed (actual) role conception.

By subtracting the categorical (observed) score from the normative (ideal) score for each item on the scale, the discrepancy score can be calculated. Discrepancy scores for each item on the scale are summed and presented as mean values for each sample on each occasion. These scores are an indication of the role frustration experienced by the sample between the ideal and observed responses. Positive role discrepancy scores show that the observed situation did not exist to the extent to which the nurse ideally thought it should, whilst negative scores show that nurses observed the situation to occur more than they thought it should.

\section{Rigour of the instrument}

The Corwin Nursing Role Conception Scales have been used internationally (Corwin \& Taves 1962, Kramer 1968, 1970, Whelan 1984, Ahmadi et al. 1987, Itano et al. 1987, Green 1988, Yung 1996). However, the location of the research, the types of educational programmes and the demography of the nursing respondents have differed. A key limitation of previous studies has been their cross-sectional design using different unmatched groups. Any longitudinal studies have tended to follow only the nurses' career aspirations and demographics (Sinclair 1984, Kemp 1985, Reid et al. 1987, Bircumshaw \& Chapman 1988, Kelly 1996).

By using a standardized instrument, the concept of nursing has been predefined by statements of what nursing is or should be. Bircumshaw (1989b) points out that the ambigu- ity over the definition of nursing is a central problem with research, which has sought to identify differences between degree and diploma nurses. The standardization of the instrument allows it to be replicated with different samples although the age of the instrument and the country of origin may reflect an earlier conceptualization of nursing in the USA. Yung (1996) and Ahmadi et al. (1987) have used modified scales to compensate and to personalize the usage but perhaps reducing generalizability of the findings. The Cronbach reliability coefficients reported in previous studies have ranged from 0.58 to 0.84 (Yung 1996). This study produced alphas of $0 \cdot 1641$ for the bureaucratic scale, 0.3972 for the professional scale and 0.6382 for the service scale. The reliability of the instrument is addressed later in this paper.

\section{Ethical considerations}

Permission to access the students was obtained through the course leader for each programme. The purpose of the study was explained to the students, along with the methods used to ensure anonymity and confidentiality. Students who agreed to take part in the study completed a written consent form. Those who did not wish to participate were assured that this would not alter the outcome of their course. Students were advised that they could withdraw from the study at any point. Data were kept in accordance with the Data Protection Act 1998 .

\section{Results}

\section{Ideal role conceptions}

\section{Bureaucratic scores}

The graduates' scores on the bureaucratic scale increased at 6 months (18.54) and then decreased at 12 months (18.14), but did not return to the initial level on graduation. The diplomates' scores, however, decreased at 6 months (18.57) and then increased at 12 months (19.24), to a similar level recorded at graduation. The sets of scores were very similar between the two groups but the diplomates' scores were higher in all cases. The scores at 12 months differed little from the scores on graduation (degree: 17.97-18.14; diploma: 19·57-19.24) (Table 2).

\section{Professional scores}

Following graduation, the graduates' scores decreased progressively over the 12 -month period. However, the diplomates mean scores rose from 24.76 at graduation to 25.85 at 6 months, but then fell to $25 \cdot 05$ at 12 months. The sets of 
Table 2 Role conceptions on graduation and at 6 and 12 months postgraduation (Ideal/Normative score)

\begin{tabular}{|c|c|c|c|c|c|c|}
\hline & \multicolumn{2}{|c|}{ Bureaucratic } & \multicolumn{2}{|c|}{ Professional } & \multicolumn{2}{|l|}{ Service } \\
\hline & Degree & Diploma & Degree & Diploma & Degree & Diploma \\
\hline Number of items & 6 & & 7 & & 7 & \\
\hline Range of possible scores & $6-30$ & & $7-35$ & & $7-35$ & \\
\hline \multicolumn{7}{|l|}{ Normative score } \\
\hline On graduation & $17 \cdot 97$ & $19 \cdot 57$ & $25 \cdot 49$ & $24 \cdot 76$ & $29 \cdot 63$ & $28 \cdot 09$ \\
\hline 6-month followup & $18 \cdot 54$ & $18 \cdot 57$ & $24 \cdot 77$ & $25 \cdot 85$ & $29 \cdot 94$ & $29 \cdot 00$ \\
\hline 12-month followup & $18 \cdot 14$ & $19 \cdot 24$ & $24 \cdot 66$ & $25 \cdot 05$ & $30 \cdot 00$ & $28 \cdot 14$ \\
\hline
\end{tabular}

scores were again very similar for the two groups, but the diplomates' scores were higher at the 6 and 12 month data collection points.

\section{Service scores}

The graduates' scores increased over the 12 months from 29.63 to $30 \cdot 00$. While the diplomates' scores increased by 6 months, they then fell at 12 months to within 0.05 of the graduating score. The graduates' scores on the same scale were higher in all cases than the diplomates.

\section{Role discrepancy}

Table 3 shows the discrepancy scores for the three scales.

\section{Bureaucratic scores}

All of the discrepancy scores for the bureaucratic scale were negative indicating that this bureaucratic domain of the nurses' role existed more in the actual work setting than their ideal perception. The degree graduates had a higher bureaucratic discrepancy score on graduation, which continued to increase at the 6- and 12-month follow-up. The diplomates' bureaucratic discrepancy scores were lower with an increase at 6 months, but a return to their original graduation score at 12 months $(-0 \cdot 29)$.

\section{Professional scores}

On graduation, the professional discrepancy score was higher for the graduates. However, at 6 months this was reversed and the discrepancy was higher for the diplomates. By 12 months, the degree graduate and diplomate scores were similar (3.41 and $3 \cdot 57$, respectively).

\section{Service scores}

Both the diplomates and graduates had high discrepancy scores indicating that the nurses perceived the service-orientated part of their role was not being practised as much as they would ideally prefer. Over the 12-month period the discrepancy scores for both groups decreased, although initially after 6 months the score slightly increased for the diplomates.

To test the statistical significance of these differences between groups, the Mann-Whitney nonparametric test was used. Nonparametric testing was chosen as the sample sizes were small, their distribution was not normal, and the range of possible responses was also limited (1-5 on the Likert scale). No statistical differences were noted between groups at any of the three time points. As there were no differences between groups, the sample was tested as a whole (degree graduates and diplomates together) to test for differences over time. No significant differences were observed, although

Table 3 Discrepancy scores

\begin{tabular}{|c|c|c|c|c|c|c|c|c|c|}
\hline & \multicolumn{3}{|c|}{ Bureaucracy } & \multicolumn{3}{|c|}{ Professional } & \multicolumn{3}{|c|}{ Service } \\
\hline & $n$ & Mean & SD & $n$ & Mean & SD & $n$ & Mean & SD \\
\hline \multicolumn{10}{|l|}{ Degree } \\
\hline On graduation & 35 & $-1 \cdot 29$ & $2 \cdot 44$ & 34 & $3 \cdot 82$ & $3 \cdot 89$ & 35 & $6 \cdot 86$ & $4 \cdot 02$ \\
\hline 6-month followup & 34 & $-1 \cdot 38$ & 3.08 & 35 & $2 \cdot 31$ & $2 \cdot 79$ & 34 & $5 \cdot 44$ & $4 \cdot 02$ \\
\hline 12-month followup & 35 & $-1 \cdot 94$ & $3 \cdot 35$ & 34 & $3 \cdot 41$ & $2 \cdot 70$ & 35 & $5 \cdot 00$ & $4 \cdot 14$ \\
\hline \multicolumn{10}{|l|}{ Diploma } \\
\hline On graduation & 21 & $-0 \cdot 29$ & $2 \cdot 10$ & 21 & $2 \cdot 81$ & $3 \cdot 03$ & 19 & $6 \cdot 74$ & $5 \cdot 18$ \\
\hline 6-month followup & 20 & $-1 \cdot 15$ & $2 \cdot 41$ & 20 & $3 \cdot 80$ & $2 \cdot 38$ & 20 & $6 \cdot 35$ & $3 \cdot 51$ \\
\hline 12-month followup & 21 & $-0 \cdot 29$ & $3 \cdot 45$ & 21 & $3 \cdot 57$ & $4 \cdot 04$ & 21 & $5 \cdot 14$ & $3 \cdot 44$ \\
\hline
\end{tabular}


the differences within service scores approached significance (Friedman: $\chi^{2}=5 \cdot 533$, d.f. $=2, P=0 \cdot 063$ ).

\section{Discussion and recommendations}

The first objective of the study was to measure the role orientation and socialization of graduates during their first year of practice. Although there were observed differences between the scores of the two groups, these differences were not statistically significant. This raises important questions about the appropriateness of the Corwin instrument and the limitations of the study. There was attrition in the sample over the study period and furthermore, the sample was a convenience sample from only two programmes. There was also no control for confounding variables such as demographics and previous experience in nursing environments. A larger sample may have been more sensitive to the discrepancy experienced by nurses in their transition from student to qualified nurse.

The lack of statistical difference in the scores may simply reflect contemporary nurse education. Nurses now have a university-based education but are required to spend the same amount of time in the clinical setting during their programme. The English National Board for Nursing, Midwifery and Health Visiting require that all students undertake 2500 hours of practice prior to registration. Consequently, their transitional experience following graduation may be characterized by more similarities than differences, particularly because of the comparable clinical experiences. In the past, studies in other countries have compared markedly different educational programmes, for example hospital vs. university-based education (e.g. Corwin 1961a, Corwin \& Taves 1962, Yung 1996).

The clinical environment that the graduates or diplomates experience in their first post and the role models that they work with may also be important. This has been found in previous research comparing role models (Wilson \& Startup 1991, Greenwood 1993, Prowse 1996).

The second objective of the study was to identify whether role orientation/socialization is influenced by educational background. The similarity in the scores of each group in this study suggests that degree and diploma graduates have few differences in their ideal role orientations to nursing. The role frustration, which they suffer on transition to the work environment, may be an occupational socialization phenomenon experienced by all regardless of educational background.

This study focused on the effect of one variable on nurse socialization, that is the educational level of the programme. Other factors impacting on nurses' role socialization remain to be examined, however. The literature highlights the transitionary role value of particular aspects of education such as role models (teachers, clinical staff), effective links between university and clinical-based learning and the use of programmes to ease the transition to qualified nurse. A more in-depth, qualitative analysis would be necessary to examine the impact of these factors on nurses' socialization. This is necessary to inform the development of a new instrument based on UK nurses' experience of their role.

The third objective of the study was to assess the appropriateness of the Corwin Nursing Role Conception Scale in measuring role socialization. The Corwin Nursing Role Conception Scale was developed over 30 years ago and since this time, nursing has undergone significant changes. The concept of the nursing role as defined by the three domains of professionalism, bureaucracy and service may now be outdated. The internal reliability scores for all three domains were low, reinforcing the probability that the instrument did not reflect contemporary UK nursing. As the instrument was developed in the USA, it may lack cultural sensitivity and further research on its applicability to the UK is required.

A further issue is that modifications to the instrument reduce generalizability and reliability. This study adapted and piloted the Corwin instrument for the first time in the UK. While it has been previously adapted for other studies (Kramer 1970, Green 1988, Yung 1996), the modifications are not usually described and the revised versions not published.

This study suggests that the differences between nurses educated through different programmes in the UK may now be small, a departure from the findings of some previous studies in other countries which compared university-based and hospital-based programmes (Corwin 1961a, 1961b, Corwin \& Taves 1962, Kramer 1968, 1970, Bullough \& Sparks 1975, Hover 1975, Yung 1996). A larger study, which explores nurses' role socialization experiences, is necessary to develop a standardized instrument for the UK. This is particularly important in the light of the findings and recommendations in 'Fitness for Practice' (UKCC 1999).

\section{Acknowledgements}

Our thanks are extended to the Oxfordshire and Berkshire Education Consortium for funding this study and to the nursing students from the two programmes who participated in it. The contributions of Chris Bulman, Oxford Brookes University and Kath Ross, University of the West of England are also gratefully acknowledged. 


\section{References}

Ahmadi K.S., Speedling E.J. \& Kuhn-Weissman G. (1987) The newly hired hospital nurse's professionalism, satisfaction and alienation. International Journal of Nursing Studies 24, 107-121.

Atkins S. \& Williams A. (1995) Registered nurses' experiences of mentoring undergraduate nursing students. Journal of Advanced Nursing 21, 1006-1015.

Bartlett H., Westcott L., Hind P. \& Taylor H. (1998) An Evaluation of Pre-Registration Nursing Education: A Literature Review and Comparative Study of Graduate Outcomes. Oxford Centre for Health Care Research \& Development, Oxford Brookes University, Oxford.

Bartlett H.P., Hind P. \& Taylor H.R. (1999) A comparison of the career aspirations of degree and P2000 diploma graduates from UK nursing programmes. Journal of Nursing Management 7, 37-43.

Bartlett H.P., Simonite V., Westcott L. \& Taylor H.R. (2000) A comparison of the nursing competence of graduates and diplomates from UK nursing programmes. Journal of Clinical Nursing 9, 369-381.

Bircumshaw D. (1989a) How can we compare graduate and nongraduate nurses? A review of the literature. Journal of Advanced Nursing 14, 438-443.

Bircumshaw D. (1989b) A survey of the attitudes of senior nurses towards graduate nurses. Journal of Advanced Nursing 14, 68-72.

Bircumshaw D. \& Chapman C.M. (1988) A follow-up of the graduates of the Cardiff bachelor of nursing degree course. Journal of Advanced Nursing 13, 273-279.

Bullough B. \& Sparks C. (1975) Baccalaureate vs associate degree nurses: the care-cure dichotomy. Nursing Outlook 23, 688-691.

Casey G. (1996) The curriculum revolution and project 2000: a critical examination. Nurse Education Today 16, 115-120.

Corwin R.G. (1961a) Role conception and career aspiration: a study of identity in nursing. Sociological Quarterly 2, 69-86.

Corwin R.G. (1961b) The professional employee: a study of conflict in nursing roles. American Journal of Sociology 66, 604-615.

Corwin R.G. \& Taves M.J. (1962) Some concomitants of bureaucratic and professional conceptions of the nurse role. Nursing Research 11, 223-227.

Davis F. \& Oleson V.L. (1964) Baccalaureate students' images of nursing: a study of change, consensus and consonance. Nursing Research 13, 8-15.

du Toit D. (1995) A sociological analysis of the extent and influence of professional socialization on the development of a nursing identity among nursing students at two universities in Brisbane, Australia. Journal of Advanced Nursing 21, 164-171.

Dunn B. (1991) A caring curriculum. Senior Nurse 11, 12-15.

Fitzpatrick J.M., While A.E. \& Roberts J.D. (1993) The relationship between nursing and higher education. Journal of Advanced Nursing 18, 1488-1497.

Fitzpatrick J.M., While A.E. \& Roberts J.D. (1996) Key influences on the professional socialization and practice of students undertaking different pre-registration nurse education programmes in the United Kingdom. International Journal of Nursing Studies 33, 506-518.

Gerrish K. (1992) The nurse teacher's role in the practice setting. Nurse Education Today 12, 227-232.
Green G.J. (1988) Relationships between role models and role perceptions of new graduate nurses. Nursing Research 37, 245248.

Greenwood J. (1993) the apparent desensitization of student nurses during their professional socialization: a cognitive perspective. Journal of Advanced Nursing 18, 1471-1479.

Hover J. (1975) Diploma vs. degree nurses: are they alike? Nursing Outlook 23, 684-687.

Itano J.K., Warren J.J. \& Ishida D.N. (1987) A comparison of role conceptions and role deprivation of baccalaureate students in nursing participating in a preceptorship or a traditional clinical program. Journal of Nursing Education 26, 69-73.

Jamal M. (1984) Job stress and job performance controversy: an empirical assessment. Organizational Behaviour and Human Performance 33, 1-21.

Jasper M. (1996) The first year as a staff nurse: the experiences of a first cohort of project 2000 nurses in a demonstration district. Journal of Advanced Nursing 24, 779-790.

Kelly B. (1991) The professional values of English nursing undergraduates. Journal of Advanced Nursing 16, 867-872.

Kelly B. (1996) Hospital nursing: 'It's a battle!' a follow-up study of English graduate nurses. Journal of Advanced Nursing 24, 10631069.

Kemp J. (1985) The graduate's progress. Nursing Times December 4, 42-43.

Kramer M. (1968) Nurse role deprivation-a symptom of needed change. Social Science and Medicine 2, 461-474.

Kramer M. (1970) Role conceptions of baccalaureate nurses and success in hospital nursing. Nursing Research 19, 428-439.

Marshall F. (1988) What is a nurse: perceptions of baccalaureate nursing students. Journal of Nurse Education 27, 185-186.

Mead G.H. (1934) Mind, Self and Society. Chicago University Press, Chicago.

Melia K. (1984) Student nurses' construction of occupational socialisation. Sociology of Health and Illness 6, 132-151.

Melia K. (1987) Learning and Working. The Occupational Socialization of Nurses. Tavistock, London.

Merton R.K., Reader G.G. \& Kendall P.L. (eds) (1957) The Students-Physician. Introductory Studies in the Sociology of Medical Education. Harvard University Press, Cambridge, MA. [Cited in Melia, K.M. (1984)].

Murray L.M. \& Morris D.R. (1982) Professional autonomy among senior nursing students in diploma, associate degree, and baccalaureate nursing programs. Nursing Research 31, 311-313.

Narcisco Throwe A. \& Fought S.G. (1987) Landmarks in the socialization process from RN to BSN. Nurse Educator 12, $15-18$.

Olesen V. \& Whittaker E. (1968) The Silent Dialogue: A Study of the Social Psychology of Professional Socialisation. Jossey Bass, San Francisco.

Prowse M.A. (1996) Linking knowledge and practice through teacher-led placements for students. Nursing Standard 10, 44-48.

Reid N.G., Nellis P. \& Boore J. (1987) Graduate nurses in Northern Ireland: their career paths, aspirations and problems. International Journal of Nursing Studies 24, 215-225.

Robinson J. (1992) Mixed Feelings. Nursing Times 88, 28-30. 
Schank M.J. \& Stollenwerk R. (1988) The leadership/management role: a differentiating factor for ADN/BSN programs? Journal of Nursing Education 27, 253-257.

Shead H. (1991) Role conflict in student nurses: towards a positive approach for the 1990s. Journal of Advanced Nursing 16, 736740.

Simpson I.H. (1967) Patterns of socialization into professions: the case of student nurses. Sociological Inquiry 37, 47-54.

Simpson I.H. (1979) From Student to Nurse. A Longitudinal Study of Socialization. Cambridge University Press, Cambridge.

Sinclair H. (1984) The careers of nurse graduates. Nursing Times 80, 56-59.
UKCC (1999) Fitness for Practice. The UKCC Commission for Nursing and Midwifery Education. UKCC, London.

Whelan E.G. (1984) Role orientation change among RNs in an upper division level baccalaureate program. Journal of Nursing Education 23, 151-155.

Wilson A. \& Startup R. (1991) Nurse socialization: issues and problems. Journal of Advanced Nursing 16, 1478-1486.

Winson G. (1993) Career paths of nurse graduates. Senior Nurse 13, $50-55$.

Yung H.H. (1996) Role conception and role discrepancy: a comparison between hospital-based and degree nursing students. Journal of Advanced Nursing 23, 184-191. 